\title{
Osseointegrated Implants and Prosthetic Reconstruction Following Skull Base Surgery
}

\author{
Shirley Hu, MD ${ }^{1}$ Demetri Arnaoutakis, $\mathrm{MD}^{2}$ Sameep Kadakia, $\mathrm{MD}^{1}$ Allison Vest, $\mathrm{MD}^{3}$ \\ Raja Sawhney, MD ${ }^{4}$ Yadranko Ducic, $\mathrm{MD}^{5}$
}

1 Division of Facial Plastic Surgery, Department of Otolaryngology-

Head and Neck Surgery, New York Eye and Ear Infirmary, New York

2 Division of Facial Plastic and Reconstructive Surgery, Department of Otolaryngology-Head and Neck Surgery, University of Texas

Southwestern Medical Center, Dallas, Texas

${ }^{3}$ Medical Art Prosthetics, LLC, McKinney, Texas

${ }^{4}$ Division of Facial Plastic Surgery, Department of OtolaryngologyHead and Neck Surgery, University of Florida College of Medicine, Gainesville, Florida

${ }^{5}$ Otolaryngology and Facial Plastic Surgery Associates,

Fort Worth, Texas

Semin Plast Surg 2017;31:214-221
Address for correspondence Yadranko Ducic, MD, Otolaryngology and Facial Plastic Surgery Associates, 923 Pennsylvania Avenue, Suite 100, Fort Worth, TX 76104 (e-mail: yducic@sbcglobal.net).
Abstract
Keywords
- skull base defects
- tumor ablative surgery
- osseointegrated implants
- prosthetics

Rehabilitation following ablative skull base surgery remains a challenging task, given the complexity of the anatomical region, despite the recent advances in reconstructive surgery. Remnant defects following resection of skull base tumors are often not amenable to primary closure. As such, numerous techniques have been described for reconstruction, including local rotational muscle flaps, pedicled flaps with skin paddle, or even free tissue transfer. However, not all patients are appropriate surgical candidates and therefore may instead benefit from nonsurgical options for functional and aesthetic restoration. Osseointegrated implants and biocompatible prostheses provide a viable alternative for such a patient population. The purpose of this review serves to highlight current options for prosthetic rehabilitation of skull base defects and describe their indications, advantages, and disadvantages.
Maxillofacial prosthetics refers to an area of dentistry dedicated to the restoration of skull base and maxillofacial defects acquired from tumor ablative surgery, trauma, or congenital defects. Anatomically, the skull base is complex and conceptually intricate due to its three-dimensional (3D) morphology. Although once considered a defect area prone to significant morbidity and poor quality of life, surgical advancements over the past decade have helped curb these fears. Prostheses have proven to be a valuable adjunct in skull base reconstruction, as these can restore function and cosmesis. The goal of this review article is to highlight current options for prosthetic rehabilitation of skull base defects with an emphasis on the advancements and limitations in the field of prosthetic reconstruction.

\section{Preoperative Planning}

Patients undergoing treatment for skull base tumors often require interdisciplinary collaboration between several clinical specialties to receive comprehensive management. ${ }^{1}$ Presurgical planning involves a concerted dialogue between the surgeons and the various disciplines of speech therapy, medical oncology, and radiation oncology. This patient population requires special needs not only for treatment but also for reconstruction and follow-up care. Prior to ablative surgery, the maxillofacial prosthodontist should be consulted to offer input regarding a patient's capacity for functional rehabilitation.
Copyright $\odot 2017$ by Thieme Medical Publishers, Inc., 333 Seventh Avenue, New York, NY 10001, USA. Tel: +1(212) 584-4662. ISSN 1535-2188. 
Multiple factors must be considered when reconstructing a skull base defect site, including size, location, and amount of adjacent supporting tissue. Large defects with abundant local tissue may be more successfully repaired with surgery than a prosthetic. ${ }^{2}$ In the setting of malignancy, the alternative use of prostheses may be beneficial if tumor surveillance is desired to prevent recurrence of disease. Another consideration is the timing of reconstruction, which can be relevant in traumatic cases or young patients born with congenital malformations. ${ }^{3}$ Patients' age in congruence with their anticipated growth must be accounted for as well. Certain prosthetics can be uniquely crafted to accommodate facial features during different growth stages.

There are specific objectives that must be fulfilled to achieve successful skull base reconstruction. These include (1) replacement of lost skin coverage, (2) watertight repair of dural defects if present, (3) intermediate placement of vascularized tissue between exposed dura and adjacent spaces, (4) provision of stable skeletal support where areas of craniofacial skeleton have been removed, (5) obliteration of dead space, and (6) rehabilitation of cranial nerve injuries. A thorough analysis of imaging studies, computed tomography $(\mathrm{CT})$, or magnetic resonance imaging (MRI) will assist in planning for the reconstruction.

Finally, the psychological state of the patients must be assessed throughout the reconstructive process; so, their goals and expectations are delineated and realistic. ${ }^{4}$ When microvascular free tissue transfer plays a role in the reconstructive paradigm, patients can expect an extensive postoperative hospital course with the potential for revision surgery and complications. ${ }^{5}$ A cost-benefit analysis of patients' desires, surgical requirements, and expected outcomes must be performed as a part of the preoperative workup. In cases of attenuated survival or elderly patients with significant comorbidities, one can argue the best option would be to pursue prosthetic rehabilitation. 6,7

\section{Prosthetic Design and Principles}

The creation of an ideal facial prosthetic addresses various factors, such as flexibility, durability, color matching, biocompatibility, hygiene, and thermal conductivity. ${ }^{8}$ The broad categories of materials used include methacrylates, polyurethane elastomers, and silicone elastomers. These are all clinically inert materials, which can absorb pigmentation to match color and texture of surrounding structures. ${ }^{9}$ Recently, silicone has become the most widely used material given its soft and flexible nature. The silicone elastomer can retain body temperature without distortion and can be stretched until transparent to blend with adjacent skin.

Advancements over the years in 3D printing technologies have tremendously improved skull base reconstruction. These digital imaging modalities can predict preoperatively a patient's defect and allow for the creation of customizable patient-specific prosthetics. ${ }^{10} \mathrm{CT}$ and MRI scans can also now be converted to a rapid prototyping model that can be printed in wax or acrylic. ${ }^{11}$ These models can be further modified or even duplicated with other prosthetic materials.

\section{Surgical Reconstruction with Native Tissue}

Large skull base defects necessitate the establishment of a foundation on which implants and prosthetics can be placed. This foundation may involve local or regional flaps or free tissue transfers.

\section{Auricular/Temporal Bone}

Reconstruction of temporal bone resections can vary from simple closure of the external auditory canal to free tissue transfer for extensive defects. The ideal reconstructive method is dictated by the type of primary lesion and tissue invasion. In particular, resection of cutaneous malignancies that involve the temporal bone often results in substantial skin and soft tissue defects of the lateral skull base with exposure of bone and/or dura. ${ }^{12}$ Adequate soft tissue coverage in such cases is the key. Skin grafts, temporalis flaps, temporoparietal fascial flaps, local rotational cutaneous flaps, lower island trapezius flaps, pectoralis flaps, free flaps (including radial forearm, rectus abdominis, latissimus dorsi, and anterolateral thigh flap [ALT]), and a combination of the aforementioned have all been described. ${ }^{12-14}$ In irradiated fields with recurrent disease affecting the auricle, local tissue coverage is prone to failure and may not be adequate, necessitating the use of myocutaneous flaps, such as the lower island trapezius flap. ${ }^{15}$

Involvement of the auricle presents a unique challenge, for which prosthetic reconstruction offers a potential solution. Total auriculectomy defects are simpler to rehabilitate than partial auriculectomy defects. Surgical alterations to enhance prosthetic prognosis are sparing of the tragus, which allows a seamless transition from native ear to prosthesis by concealing the anterior margin behind the posterior flexure, and lining of the defect with a split-thickness skin graft. The area of the defect must be flat or concave for the prosthesis to fit properly and aesthetically. For placement of anchoring osseointegrated implants (OIs), the recipient bone must be well vascularized and have adequate thickness (greater than $2.5 \mathrm{~mm}$ ) to support the load of the prosthesis. ${ }^{16-18}$

\section{Orbit/Nose}

Extensive skull base surgery may often violate the orbit. For the successful fabrication and engagement of an orbital prosthesis, care must be taken to attain sufficient depth of the defect. ${ }^{19}$ Thus, free tissue transfers should be used with care when filling an orbital defect, particularly when the adjacent orbital walls are left in situ and if no subsequent irradiation is planned. However, lateral and medial facial orbital defects can be resurfaced with flaps, such as the radial forearm or a thinned ALT. The bony inferior orbital rim should be recreated and have the stability to support a prosthetic load. This can be achieved with bone grafts harvested from the rib in conjunction with rectus abdominis flaps. A split-thickness skin graft is placed to line any exposed bone of the orbital cavity and create an adhesive base for the implant. Importantly, the eyelid must be resected and the position of the eyebrow maintained for the most aesthetic result. $^{20-23}$ 
Nasal resections are often reconstructed with regional flaps, such as the paramedian forehead flap. However, prosthetic rehabilitation may be preferred in the irradiated field and can provide an acceptable functional and aesthetic result. As with the orbit, prosthetic prognosis is improved when there is sufficient access of the prosthesis to the defect. Specifically, residual elements such as the nasal bones, ala, and anterior nasal septum that render restoration of proper size and symmetry difficult may need to be removed. Grafts or flaps can be used to maintain the normal position and contour of the nasolabial folds and upper lip. ${ }^{20-22} \mathrm{~A}$ split-thickness skin graft placed to line the nasal floor and any exposed bone would also limit contracture and elevation of the upper lip and provide a stable platform for the nasal prosthesis.

\section{Maxillary/Midface}

The midface encompasses the most prominent features of the face and separates the oral cavity from the orbital cavity. Commonly, midface defects are complex 3D defects involving both soft and bony tissues. The ultimate objectives are to separate the oral, sinonasal, orbital, and intracranial cavities; eliminate dead space and cover exposed dura; restore the functions of speech, swallowing, and mastication; replace the skeletal framework; and achieve the best cosmesis possible.

Free tissue transfers are well suited for reconstruction of large entry wound defects, and the freedom of their design and inset allows for great versatility in functional reconstruction. The choice of the ideal free flap is contingent upon the extent of the defect. Type I and II defects can be reconstructed with the radial forearm free flap (preferable for its flexibility, safety, and reliability) and combined with either a small portion of radius or bone graft if bone is required. ${ }^{24}$ Type III and IV defects require bulkier tissue, and the rectus abdominis, latissimus dorsi, and scapular free flaps are viable options. In addition, perforator flaps, specifically the ALT flap, are now frequently the primary choice for any head and neck soft tissue defect. ${ }^{25-28}$

Bone-containing flaps are another option for reconstruction, particularly when the defect involves the maxillary arch, orbital floor, or maxillary buttresses. Successful reconstruction requires an osseous component that transmits occlusal forces to the cranium, resists resorption, and allows functional and cosmetic rehabilitation with OI. ${ }^{29}$ Options include flaps containing fibula, iliac crest, and rib, such as the latissimus dorsi and rectus abdominis flaps. The fibular free flap has several advantages. It provides a sufficient length of bone that can be segmented to reapproximate the contour of the alveolar ridge. ${ }^{30}$ In addition, its bicortical configuration and superior vertical height make it the ideal choice for OI placement. Thus, for complex reconstructions of extensive defects in the midfacial area, microvascular free tissue transfer in combination with extraoral implants and craniofacial prosthetic work may yield more reasonable functional and aesthetic outcomes and improve the quality of life. ${ }^{31-33}$

The reconstructive surgeon can utilize various surgical techniques to optimize prosthetic rehabilitation. For instance, split-thickness skin grafts or allogenic material can be placed into maxillary defects, allowing an excellent scar tissue band for retention of the OI prosthesis and improved oral hygiene. ${ }^{20,34}$ All raw surfaces, potential support surfaces, and useful undercuts should be lined with skin grafts to enhance engagement with prostheses.

\section{Retention Systems|Osseointegrated Implants}

Prior to the concept of osseointegration, facial prostheses were often mechanically anchored to spectacles or even secured through anatomical undercuts in the early 20th century. ${ }^{35}$ Complications with these older retention systems led to advancements in prosthetic anchoring. Medical adhesives were developed as an easy-to-use alternative. However, these often lose their bone strength as the adhesive weakens over time, requiring reapplication every 4 to 8 hours. Patients with active lifestyles are poor candidates, as the adhesive-based prosthesis can be easily dislodged with constant movement. ${ }^{36}$ Low compliance and patient dissatisfaction with daily-applied prosthetic adhesives fueled interest in other anchorage methods. ${ }^{37}$

An alternative method involves craniofacial endosseous implants. Advantages of such implants include easier maintenance of the prosthesis, avoiding the need for skin adhesives and tunnels that often limit patient activity, and allowing for improved hygiene, patient comfort, and satisfaction; higher retention rates; increased accuracy and stability of prosthesis placement; and longer lifespan of the facial prosthesis. ${ }^{38,39}$ Implant success rates are largely dependent on the implant location and the target tissue's radiation status. Rates vary from 81 to $100 \%$ in the mastoid region, 45 to $100 \%$ in the orbit, and 46 to $100 \%$ in the nasal floor. ${ }^{35}$

Two critical processes must occur for successful rigid fixation of an alloplastic implant to bone: osteoinduction and osteoconduction. ${ }^{40}$ The terms osteoinduction, osteoconduction, and osseointegration are infrequently used correctly. Osteoinduction is the process by which osteogenesis is induced, a phenomenon regularly seen in any bone healing process. ${ }^{41}$ It implies the recruitment of immature cells and the stimulation of these cells to develop into preosteoblasts. Implants introduced into the bone within the defect site trigger osteoinduction. After the implants are placed, osteoconduction begins, which refers to the development of bone growing on a surface. This depends on the action of differentiated bone cells, which originate either in preexisting osteoblasts or cells recruited from mesenchymal cells by osteoinduction. ${ }^{42}$ Therefore, in the practical sense, osteoconduction relies significantly on previous osteoinduction as is regularly seen in the case of bone implants. Osseointegration refers to the stable anchorage of an implant achieved by direct bone-to-implant contact. ${ }^{43} \mathrm{In}$ craniofacial implantology, this mode of anchorage is the only one for which high success rates have been reported.

Osseointegration came into favor during the 1970s when Swedish physicians discovered that titanium was biocompatible with bone. ${ }^{44}$ The bone-anchored hearing aid was the first application outside the oral cavity of a bone-anchored implant. This device allows sound energy to be transmitted directly to the skull base via an attachable vibrator, and with this development ushered in a new era of hearing rehabilitation. With time, physicians discovered several benefits with bone- 
anchored hearing aids over traditional bone-conduction hearing aids, including superior sound transmission and decreased skin pressure. ${ }^{45}$ Not long after the implantation of boneanchored hearing aids, osseointegrated abutments were crafted to anchor prostheses for the nose, ear, orbit, and midface in the reconstruction of craniofacial defects. ${ }^{46}$ Bone-anchored implants are now a mainstay of prosthetic fixation for auricular defects and have also been successfully incorporated into the armamentarium for the rehabilitation of other craniofacial defects. $^{35,39,47,48}$

Several mechanisms exist that allow coupling of the OI with the external prosthesis. Such examples include bar-clip attachments, ball attachments, and magnetic retention. ${ }^{49,50}$ Bar-clip retention remains the most widely used for facial prostheses and provides the strongest bond. However, magnetic retention offers strong attractive forces in small and inconspicuous shapes that are preferred for craniofacial deficits. ${ }^{51}$ For example, orbital and nasal prostheses are almost exclusively retained in place by magnets. Bone-anchored prostheses typically last from 3 to 5 years compared with 1 to 3 years for an adhesive-retained prosthesis.

Although application of OIs is a relatively straightforward procedure, there are patient-specific risk factors for potential complications. Not surprisingly, previous irradiation predisposes to implant extrusion. ${ }^{39}$ The risk for osteoradionecrosis (ORN) always lingers in previously irradiated patients, prompting some providers to offer hyperbaric oxygen therapy. ${ }^{52}$ In addition, any trauma-induced or spontaneous tissue breakdown can result in a nonhealing wound that leads to ORN. The benefit of vascularized tissue to protect the underlying bone from the harmful effects of radiation cannot be understated. It is prudent to cover the projected implant site with a local flap or free tissue transfer at the time of tumor ablation when postoperative adjuvant radiation therapy is indicated.

\section{Prostheses}

\section{Auricular}

Auricular defects can be congenital in nature, such as TreacherCollins syndrome or other second arch insults that result in microtia, trauma, or following ablative cancer surgery. Indications for repair with a prosthesis are based on the extent of the defect, as large areas prove more difficult to repair surgically. Local skin and subcutaneous tissues must remain intact with a rich blood supply to support transplanted autologous grafts. ${ }^{53}$ Often, several procedures are needed for graft harvesting, tissue expansion, and cosmetic fine tuning, which subject the patient to morbidity and possible complications. An Italian study actually showed bleeding, infection, and hematoma to be more frequent with autologous grafting at the implant and graft site than in an auricular prosthesis. ${ }^{54}$ Furthermore, patient satisfaction is frequently lower due to inconsistent cosmetic outcomes. ${ }^{55}$

If a prosthesis is favored, tragal preservation can help conceal the anterior margin of the prosthesis. ${ }^{56}$ As previously described, OIs can improve retention of the prosthesis and have a high degree of success in the temporal bone. ${ }^{57}$ If a hearing deficit accompanies microtia, use of a bone-anchored hearing aid can offer improvement in bone conduction. Implants can often be placed into three locations that correspond with the 1 , 3 , and 5 o'clock positions of the left ear and the 7, 9, and 11 o'clock positions of the right ear. These locations have been shown to lend greater infrastructure support and allow for abutment attachment in a correct high anatomical location. ${ }^{58}$ The temporal bone must retain blood supply and thickness (greater than $2.5 \mathrm{~mm}$ ) to support the load of the prosthesis. Preoperative CT imaging can help survey the integrity of the temporal bone and map out adequate sites for implants. ${ }^{59}$

\section{Orbital}

Following the removal of the eye, an orbital implant is initially inserted into the anophthalmic cavity to provide adequate volume replacement, up to $75 \%$ of the original ocular globe, and to restore the aesthetic appearance of a normal eye. ${ }^{60}$ There are two types of implants, integrated and nonintegrated. The former is usually made from porous materials, such as hydroxyapatite, porous polyethylene, and aluminum oxide, ${ }^{61}$ while nonintegrated implants consist of nonporous materials, such as polymethylmethacrylate and silicone. Porous materials have gained prominence, since their highly interconnected porous architecture allows for fibrovascular ingrowth of host tissue, improved stability, decreased complication rates, and the option of pegging or posting to enhance the motility of the artificial eye. ${ }^{62,63}$ However, current evidence has very low certainty and is not sufficient to assess the difference in effect between integrated and nonintegrated material orbital implants for treating anophthalmia. ${ }^{64}$

An orbital or ocular prosthesis fits over the orbital implant and under the eyelid. Prostheses are often made of acrylic, glass, or silicone spheres. Prostheses may be either stock or custom made. Stock eyes, while easier to insert, fit inadequately and must be removed several times a day to be cleaned. Custom-made prosthetics, on the other hand, have improved adaptation and subsequently better mobility. ${ }^{65}$ Retention of an orbital prosthesis is most successful with osseointegration. ${ }^{66}$ Adhesive retention should thus be used in patients with incomplete bone growth or low bone density. - Figs. 1 and 2 show a patient following orbital exenteration for malignancy followed by prosthetic reconstruction.

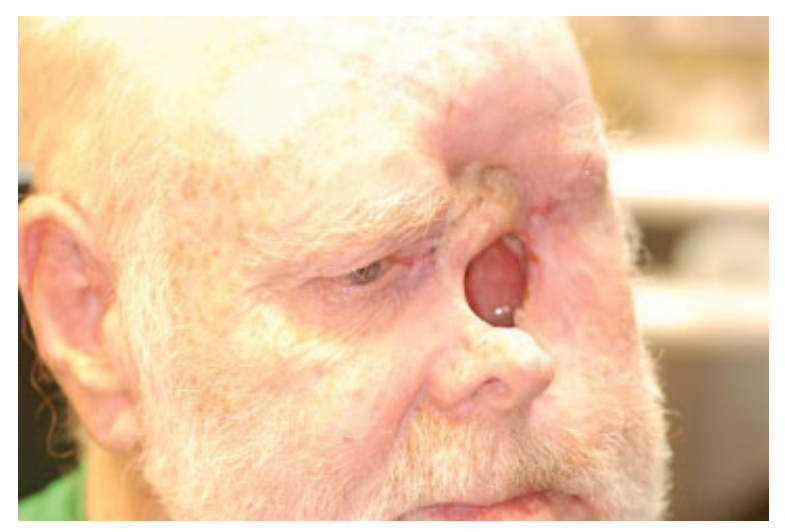

Fig. 1 A male patient following orbital exenteration for malignancy showing a visible defect in the lateral nasal wall and orbital cavity (Photograph was used with patient's permission). 


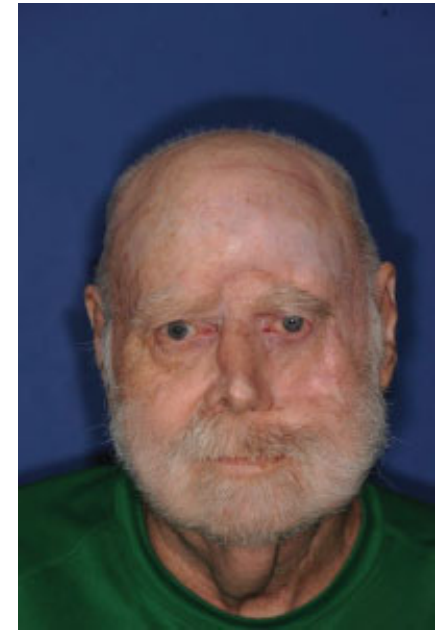

Fig. 2 Patient reconstructed with orbital prosthesis (Photograph was used with patient's permission).

\section{Nasal}

In extensive full-thickness defects of the nose, particularly in elderly subjects or patients with poor general health status, the use of a nasal prosthesis represents an acceptable alternative to surgical reconstruction, especially when the entire nasal pyramid is affected. 5,67

While osseointegration has significantly improved nasal implant retention, its success is contingent on the available bone stock. ${ }^{31,68-70}$ Traditionally, implants are inserted into the floor of the nasal cavity or glabella. Limitations in the quality or quantity of the recipient bone can compromise the stability or cause dislodgement of an implant with functional movements such as mastication. ${ }^{31,70}$ Several studies have evaluated the effect of zygomatic implants in supporting a nasal prosthesis. ${ }^{71-73}$ The density and volume of the zygoma facilitate osseointegration, ${ }^{71}$ and the location of the zygo-

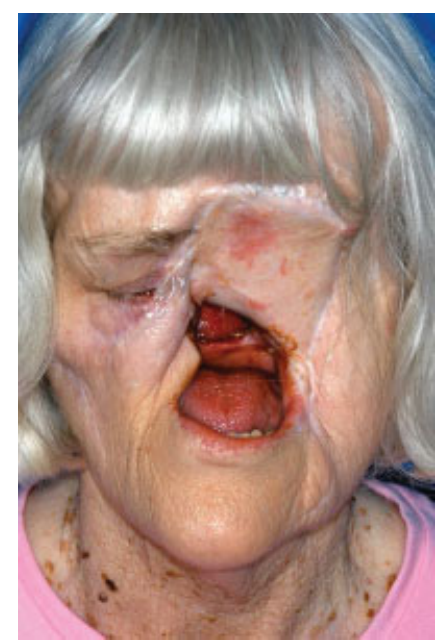

Fig. 3 A female patient following extensive midfacial and orbital resection for malignancy and reconstruction with initial soft tissue flap (Photograph was used with patient's permission).

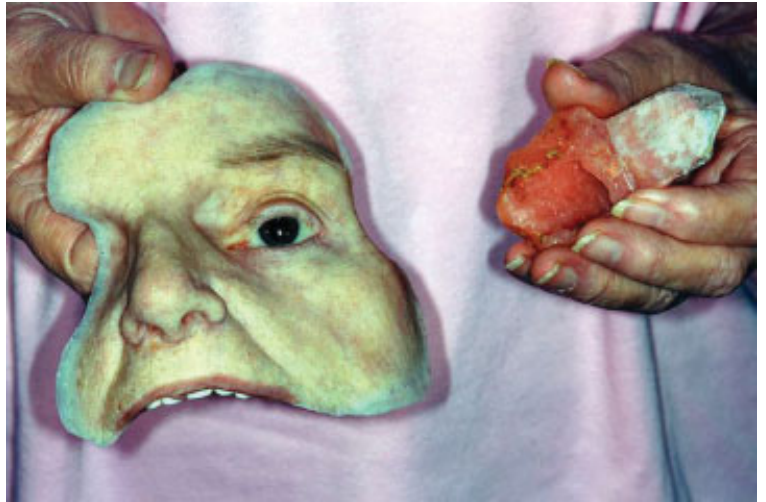

Fig. 4 Photograph of designed midface and orbital prosthesis and mounting system.

matic implant is often not in the field of radiation therapy, further contributing to implant success. ${ }^{72}$

The manufacturing of a nasal prosthesis involves taking an imprint of the affected area, producing a cast from the imprint, casting the final prosthesis, and painting the details that give the prosthesis its unique appearance. ${ }^{74}$ Typically made of polydimethylsiloxane, a nasal prosthesis is flexible and mobilizes with the skin. As with other prostheses, a nasal prosthesis may be fixed anatomically to existing structures (bony undercuts), mechanically (to spectacle frames), chemically (gluedon nasal prosthesis), or, as discussed before, surgically, using osseointegrated retention systems. ${ }^{75,76}$ One of the drawbacks of a nasal prosthesis is that it does not provide a definitive solution, since both the surrounding area and the prosthetic material itself are subject to increased rigidity and altered appearance such as discoloration over time. ${ }^{74}$

\section{Maxillary/Midface}

With extensive maxillary defects involving the palate and facial tissue, surgical intervention with skin grafts and osteocutaneous free flaps may not produce the most desirable outcome. ${ }^{77}$

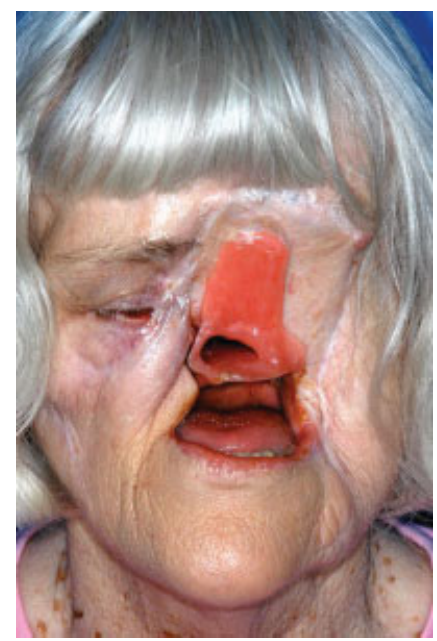

Fig. 5 Placement of mounting system in central portion of face (Photograph was used with patient's permission). 


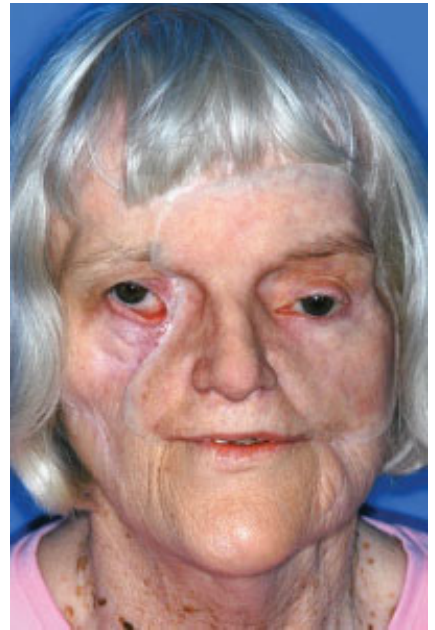

Fig. 6 Photograph of patient following placement of prosthesis (Photograph was used with patient's permission).

Such defects are also inadequately addressed by obturators, since the ability to stabilize an obturator framework diminishes with an increase in size of the maxillary defect and a decrease in remaining dentition and palatal supporting area. ${ }^{78}$ In cases when soft tissue is unavailable to form a seal with the prosthesis, OIs are indicated for insertion and fixation of the prosthesis. Three to four implants are typically required for sufficient support. ${ }^{79}$ The zygomatic buttress, supraorbital rim, vomer, and horizontal part of the hard palate are stable recipient sites. ${ }^{56}$ It is critical to preserve any remnant palate, premaxilla, and/or adjacent abutment tooth for stability and retention of the prosthesis. ${ }^{80}$ Forces that affect the fit of a prosthesis must be considered and include the downward gravitational forces, upward occlusive forces, and torsional forces involved in functional speech, swallowing, and mastication. ${ }^{34,81}$

The maxillary prosthesis necessitates individual fabrication for complex midface defects. Alloplastic prostheses provide an obturator function between the orbital, maxillary, and oral cavities, as well as an external coverage. Midface prostheses frequently consist of acrylic, silicone, or other polymers and can be removed, cleaned, and reinserted. ${ }^{82}$ Maintenance remains the greatest factor in influencing patient preference between prosthetic rehabilitation and surgical reconstruction. ${ }^{77}$ - Figs. 3 to 6 show a patient following multiple surgeries for oncologic resection following reconstruction with a full midfacial and orbital prosthesis.

\section{Conflict of Interest}

None.

\section{References}

1 Gibson MK, Forastiere AA. Multidisciplinary approaches in the management of advanced head and neck tumors: state of the art. Curr Opin Oncol 2004;16(03):220-224

2 Bhandari S. Prosthetic considerations in oral and maxillofacial trauma. Journal of Postgraduate Med Educ Res 2014;48(02):87-90
3 Thaller SR, Bradley JP, Garri JI. Craniofacial Surgery. New York, NY: Informa Healthcare, Inc.; 2008

4 Wiens JP, Wiens RL. Psychological management of the maxillofacial prosthetic patient. In: Taylor TD, ed. Clinical Maxillofacial Prosthetics. Hanover Park, Illinois, IL: Quintessence Publishing; 2000:1-14

5 de Bree R, Leemans CR. Recent advances in surgery for head and neck cancer. Curr Opin Oncol 2010;22(03):186-193

6 Moreno MA, Skoracki RJ, Hanna EY, Hanasono MM. Microvascular free flap reconstruction versus palatal obturation for maxillectomy defects. Head Neck 2010;32(07):860-868

7 Markt JC, Lemon JC. Extraoral maxillofacial prosthetic rehabilitation at the M. D. Anderson Cancer Center: a survey of patient attitudes and opinions. J Prosthet Dent 2001;85(06):608-613

8 Montgomery PC, Kiat-Amnuay S. Survey of currently used materials for fabrication of extraoral maxillofacial prostheses in North America, Europe, Asia, and Australia.J Prosthodont 2010;19(06):482-490

9 Federspil PA. Implant-retained craniofacial prostheses for facial defects. GMS Curr Top Otorhinolaryngol Head Neck Surg 2009;8: Doc03

10 Feng Z, Dong Y, Zhao Y, et al. Computer-assisted technique for the design and manufacture of realistic facial prostheses. Br J Oral Maxillofac Surg 2010;48(02):105-109

11 Subburaj K, Nair C, Rajesh S, Meshram SM, Ravi B. Rapid development of auricular prosthesis using CAD and rapid prototyping technologies. Int J Oral Maxillofac Surg 2007;36(10):938-943

12 Gal TJ, Kerschner JE, Futran ND, et al. Reconstruction after temporal bone resection. Laryngoscope 1998;108(4 Pt 1):476-481

13 Cheney ML, Varvares MA, Nadol JB Jr. The temporoparietal fascial flap in head and neck reconstruction. Arch Otolaryngol Head Neck Surg 1993;119(06):618-623

14 Iseli TA, Yelverton JC, Iseli CE, Carroll WR, Magnuson JS, Rosenthal EL. Functional outcomes following secondary free flap reconstruction of the head and neck. Laryngoscope 2009;119(05):856-860

15 Neligan PC, Mulholland S, Irish J, et al. Flap selection in cranial base reconstruction. Plast Reconstr Surg 1996;98(07):1159-1166 , discussion; 1167-1168

16 Giot JP, Labbé D, Soubeyrand E, et al. Prosthetic reconstruction of the auricle: indications, techniques, and results. Semin Plast Surg 2011;25(04):265-272

17 Mardani MA, Aminian G, Tabatabaian F, Arazpour M, Hutchins SW, Head JS. A novel technique for fabricating an ear prosthesis in a patient with congenital ear deformity. Prosthet Orthot Int 2013; 37(04):340-343

18 Badie-Modiri B, Kaplanski P. Extra-oral implants: principal areas of implantation [Article in French]. Rev Stomatol Chir Maxillofac 2001;102(05):229-233

19 Gliklich RE, Rounds MF, Cheney ML, Varvares MA. Combining free flap reconstruction and craniofacial prosthetic technique for orbit, scalp, and temporal defects. Laryngoscope 1998;108(4 Pt 1):482-487

20 Chambers MS, Lemon JC, Martin JW. Surgical techniques to enhance prosthetic rehabilitation. In: Bailey BJ, Johnson JT, Newlines S, eds. Head and Neck Surgery-Otolaryngology. 4th ed. Philadelphia, PA: Lippincott Williams and Wilkins; 2006: 1853-1865, Chapter 127

21 Lemon JC, Martin JW, Jacob RF. Prosthetic rehabilitation. In: Weber RS, Miller MJ, Goepfert H, eds. Basal and Squamous Cell Skin Cancers of the Head and Neck. Baltimore: Williams \& Wilkins; 1996:305-312

22 King GE, Jacob RF, Martin JW. Oral and dental rehabilitation. In: Johns ME, ed. Complications in Otolaryngology Head and Neck Surgery. Philadelphia, PA: BC Decker; 1986:131

23 Lemon JC, Chambers MS. Conventional methods of retention of facial prostheses. First International Congress on Max Fac Prosthetics 1994;1:116-119

24 Cordeiro PG, Santamaria E. A classification system and algorithm for reconstruction of maxillectomy and midfacial defects. Plast Reconstr Surg 2000;105(07):2331-2346; discussion 2347-2348 
25 Wei FC, Jain V, Celik N, Chen HC, Chuang DC, Lin CH. Have we found an ideal soft-tissue flap? An experience with 672 anterolateral thigh flaps. Plast Reconstr Surg 2002;109(07):2219-2226; discussion 2227-2230

26 Ozkan O, Coşkunfirat OK, Ozgentaş HE. An ideal and versatile material for soft-tissue coverage: experiences with most modifications of the anterolateral thigh flap. J Reconstr Microsurg 2004;20(05):377-383

27 Coskunfirat OK, Wei FC, Huang WC, Cheng MH, Yang WG, Chang YM. Microvascular free tissue transfer for treatment of osteoradionecrosis of the maxilla. Plast Reconstr Surg 2005;115(01):54-60

28 Ozkan O, Mardini S, Chen HC, Cigna E, Tang WR, Liu YT. Repair of buccal defects with anterolateral thigh flaps. Microsurgery 2006; 26(03):182-189

29 Funk GF, Arcuri MR, Frodel JL Jr. Functional dental rehabilitation of massive palatomaxillary defects: cases requiring free tissue transfer and osseointegrated implants. Head Neck 1998;20(01):38-51

30 Hanasono MM, Hofstede TM. Craniofacial reconstruction following oncologic resection. Neurosurg Clin N Am 2013;24(01):111-124

31 Mueller S, Hohlweg-Majert B, Buergers R, et al. The functional and aesthetic reconstruction of midfacial and orbital defects by combining free flap transfer and craniofacial prosthesis. Clin Oral Investig 2015;19(02):413-419

32 Vander Poorten V, Meulemans J, Delaere P. Midface prosthetic rehabilitation. Curr Opin Otolaryngol Head Neck Surg 2016;24 (02):98-109

33 Streit L, Dražan L, Hýža P, et al. Reconstruction of large facial and orbital defects by combining free flap transfer with craniofacial prosthesis. Acta Chir Plast 2016;58(02):77-81

34 Aramany MA. Basic principles of obturator design for partially edentulous patients. Part II: design principles. J Prosthet Dent 1978;40(06):656-662

35 Visser A, Raghoebar GM, van Oort RP, Vissink A. Fate of implantretained craniofacial prostheses: life span and aftercare. Int J Oral Maxillofac Implants 2008;23(01):89-98

36 Kiat-Amnuay S, Gettleman L, Goldsmith LJ. Effect of multi-adhesive layering on retention of extraoral maxillofacial silicone prostheses in vivo. J Prosthet Dent 2004;92(03):294-298

37 Wondergem M, Lieben G, Bouman S, van den Brekel MW, Lohuis PJ. Patients' satisfaction with facial prostheses. Br J Oral Maxillofac Surg 2016;54(04):394-399

38 Cobein MV, Coto NP, Crivello Junior O, et al. Retention systems for extraoral maxillofacial prosthetic implants: a critical review. $\mathrm{Br}$ J Oral Maxillofac Surg 2017. [Epub ahead of print] Doi: 10.1016/j. bjoms.2017.04.012

39 Granström G. Craniofacial osseointegration. Oral Dis 2007;13 (03):261-269

40 Albrektsson T. Dental and maxillofacial implantology. In: Hobkirk JA, Watson K, eds. Principles of Osseointegration. London: Mosby-Wolfe; 1995:9-19

41 Wilson-Hench J. Osteoinduction. Definitions in biomaterials. In: Williams DF, ed. Progress in Biomedical Engineering, Vol 4. Amsterdam: Elsevier; 1987:29

42 Frost HM. The biology of fracture healing. An overview for clinicians. Part I. Clin Orthop Relat Res 1989;(248):283-293

43 Albrektsson T, Brånemark PI, Hansson HA, Lindström J. Osseointegrated titanium implants. Requirements for ensuring a longlasting, direct bone-to-implant anchorage in man. Acta Orthop Scand 1981;52(02):155-170

44 Branemark PI, Hansson BO, Adell R, et al. Osseointegrated titanium implants in the treatment of the edentulous jaw experience from a 10-year period. Scand J Plast Reconstr Surg 1977;16:1-132

45 Tjellström A, Håkansson B. The bone-anchored hearing aid. Design principles, indications, and long-term clinical results. Otolaryngol Clin North Am 1995;28(01):53-72

46 Reyes RA, Tjellström A, Granström G. Evaluation of implant losses and skin reactions around extraoral bone-anchored implants: a 0- to 8year follow-up. Otolaryngol Head Neck Surg 2000;122(02):272-276
47 Karakoca S, Aydin C, Yilmaz H, Bal BT. Retrospective study of treatment outcomes with implant-retained extraoral prostheses: survival rates and prosthetic complications. J Prosthet Dent 2010; 103(02):118-126

48 Parel SM, Phillips WR. A risk assessment treatment planning protocol for the four implant immediately loaded maxilla: preliminary findings. J Prosthet Dent 2011;106(06):359-366

49 de Sousa AA, Mattos BS; Sousa de. Magnetic retention and bar-clip attachment for implant-retained auricular prostheses: a comparative analysis. Int J Prosthodont 2008;21(03):233-236

50 Voigt A, Christ S, Klein M. Experimental analysis of retention forces of different magnetic devices for bone-anchored auricular facial prostheses. Int J Oral Maxillofac Surg 2008;37(07):664-668

51 Ariani N, Visser A, van Oort RP, et al. Current state of craniofacial prosthetic rehabilitation. Int J Prosthodont 2013;26(01):57-67

52 Granström G, Tjellström A, Brånemark PI. Osseointegrated implants in irradiated bone: a case-controlled study using adjunctive hyperbaric oxygen therapy. J Oral Maxillofac Surg 1999;57 (05):493-499

53 Cox A, Sabbagh W, Gault D. Costal cartilage or conchal cartilage for aesthetic and structural reconstruction of lower pole ear defects. Aesthet Surg J 2012;32(03):271-274

54 Mevio E, Facca L, Schettini S, Mullace M. Bone-anchored titanium implants in patients with auricular defects: three years and 27 patients' experience. Int J Otolaryngol 2016;2016:9872048

55 Zhao Y, Wang Y, Zhuang H, et al. Clinical evaluation of three total ear reconstruction methods. J Plast Reconstr Aesthet Surg 2009; 62(12):1550-1554

56 Lemon JC, Kiat-amnuay S, Gettleman L, Martin JW, Chambers MS Facial prosthetic rehabilitation: preprosthetic surgical techniques and biomaterials. Curr Opin Otolaryngol Head Neck Surg 2005;13 (04):255-262

57 Nishimura RD, Roumanas E, Sugai T, Moy PK. Auricular prostheses and osseointegrated implants: UCLA experience. J Prosthet Dent 1995;73(06):553-558

58 Wright RF, Zemnick C, Wazen JJ, Asher E. Osseointegrated implants and auricular defects: a case series study. J Prosthodont 2008;17(06):468-475

59 Badie-Modiri B, Kaplanski P. Extra-oral implants: principal areas of implantation [Article in French]. Rev Stomatol Chir Maxillofac 2001;102(05):229-233

60 Hughes MO. A pictorial anatomy of the human eye/anophthalmic socket: a review for ocularists. J Ophthalmic Prosthet 2007; 12:51-63

61 Begum Z, Kola MZ, Joshi P. Analysis of the properties of commercially available silicone elastomers for maxillofacial prostheses. Int J Contemp Dent 2011;2(04):1-5

62 Cafiero-Chin M, Marques C, Danz HJ. Ocular prosthesis: indications to management. Can J Optom 2015;77:24-32

63 Baino F, Perero S, Ferraris S, et al. Biomaterials for orbital implants and ocular prostheses: overview and future prospects. Acta Biomater 2014;10(03):1064-1087

64 Schellini S, El Dib R, Silva LR, Farat JG, Zhang Y, Jorge EC. Integrated versus non-integrated orbital implants for treating anophthalmic sockets. Cochrane Database Syst Rev 2016;11:CD010293

65 Da Costa GC, Aras MA, Chalakkal P, Da Costa MC. Ocular prosthesis incorporating IPS e-max press scleral veneer and a literature review on non-integrated ocular prosthesis. Int J Ophthalmol 2017;10(01):148-156

66 Moran WJ, Toljanic JA, Panje WR. Implant-retained prosthetic rehabilitation of orbital defects. Arch Otolaryngol Head Neck Surg 1996;122(01):46-50

67 Raghoebar GM, van Oort RP, Roodenburg JL, Reintsema H, Dikkers FG. Fixation of auricular prostheses by osseointegrated implants. J Invest Surg 1994;7(04):283-290

68 Ciocca L, Maremonti P, Bianchi B, Scotti R. Maxillofacial rehabilitation after rhinectomy using two different treatment options: clinical reports. J Oral Rehabil 2007;34(04):311-315 
69 Seçilmiş A, Oztürk AN. Nasal prosthesis rehabilitation after partial rhinectomy: a clinical report. Eur J Dent 2007;1(02):115-118

70 Dimitroulis G. Nasal implants following nasectomy. Int J Oral Maxillofac Surg 2007;36(05):447-449

71 Scott N, Kittur MA, Evans PL, Dovgalski L, Hodder SC. The use of zygomatic implants for the retention of nasal prosthesis following rhinectomy: the Morriston experience. Int J Oral Maxillofac Surg 2016;45(08):1044-1048

72 Brånemark PI, Adell R, Albrektsson T, Lekholm U, Lindström J, Rockler B. An experimental and clinical study of osseointegrated implants penetrating the nasal cavity and maxillary sinus. J Oral Maxillofac Surg 1984;42(08):497-505

73 Chrcanovic BR, Albrektsson T, Wennerberg A. Survival and complications of zygomatic implants: an updated systematic review. J Oral Maxillofac Surg 2016;74(10):1949-1964

74 Malard O, Lanhouet J, Michel G, Dreno B, Espitalier F, Rio E. Fullthickness nasal defect: place of prosthetic reconstruction. Eur Ann Otorhinolaryngol Head Neck Dis 2015;132(02):85-89

75 Flood TR, Russell K. Reconstruction of nasal defects with implantretained nasal prostheses. Br J Oral Maxillofac Surg 1998;36(05): 341-345
76 Ethunandan M, Downie I, Flood T. Implant-retained nasal prosthesis for reconstruction of large rhinectomy defects: the Salisbury experience. Int J Oral Maxillofac Surg 2010;39(04): 343-349

77 Okay DJ, Genden E, Buchbinder D, Urken M. Prosthodontic guidelines for surgical reconstruction of the maxilla: a classification system of defects. J Prosthet Dent 2001;86(04):352-363

78 Beumer J, Curtis TA, Marunick MT, eds. Maxillofacial Rehabilitation: Prosthodontic and Surgical Consideration. 2nd ed. St. Louis, Missouri, MO: Ishiyaku Euroamerica Inc; 1996

79 Wolfaardt J, Gehl G, Farmand M, Wilkes G. Indications and methods of care for aspects of extraoral osseointegration. Int $\mathrm{J}$ Oral Maxillofac Surg 2003;32(02):124-131

80 Murat S, Gurbuz A, Isayev A, Dokmez B, Cetin U. Enhanced retention of a maxillofacial prosthetic obturator using precision attachments: two case reports. Eur J Dent 2012;6(02):212-217

81 Parr GR, Tharp GE, Rahn AO. Prosthodontic principles in the framework design of maxillary obturator prostheses. 1989. J Prosthet Dent 2005;93(05):405-411

82 Özkan O, Coşkunfirat OK, Özkan O. Midface reconstruction. Semin Plast Surg 2010;24(02):181-187 